\title{
RESEARCH SKILLS IN TRANSLATION STUDIES: WHAT WE NEED TRAINING IN
}

\author{
ANTHONY PYM \\ Professor Extra-ordinary, Department of Afrikaans and Dutch \\ University of Stellenbosch, South Africa \\ E-mail: anthony.pym@urv.cat
}

\begin{abstract}
This paper reports on evaluative comments made over some ten years on research by students in the doctoral program in Translation and Intercultural Studies at the Universitat Rovira i Virgili in Tarragona, Spain. The vast majority of the comments are found to involve general shortcomings that do not particularly concern Translation Studies. This would suggest that research trainees do not really need a doctoral program in Translation Studies. Other weaknesses stem from the relatively undeveloped intellectual position of Translation Studies as a discipline, especially with regard to unstable terminology, the attribution of authority to other disciplines, and tendencies to disappear into philosophical aporias, into indiscriminate data-gathering, and into the uncritical extension of vocational values or professional best practices. Some shortcomings, however, would seem more germane to the nature of translation as an object of knowledge. This particularly concerns the problems of describing translation quality and attempts to position the researcher as being external to the intercultural processes being investigated. Translation researchers, it is argued, are necessarily interpreting language in a way similar to translators, operating on the borders between stabilizing systems. That special position, which is specific in terms of degree rather than kind, makes hermeneutic work and self-reflection basic parts of translation research, and trainees need to develop the corresponding awareness. On the other hand, to limit oneself to empirical and often positivistic methodologies from other disciplines would be to de-intellectualize the way researchers engage socially and politically with translation.
\end{abstract}

Keywords: research methods, research training, hermeneutics, epistemology, translation quality, activism

\section{INTRODUCTION}

I have been running a doctoral program in Translation Studies in Tarragona, Spain, for very nearly ten years; I am now reflecting on that experience with a view to informing the doctoral program in Translation Studies in Stellenbosch, South Africa.

Over those ten years in Tarragona we have seen exactly 100 students enter the program (in recent years they start in the research Masters that now initiates the program). About one in ten of those starters will probably defend their doctoral dissertation within five years. That low rate is not what particularly worries me, since there are many real-world circumstances that account for it. What 
concerns me far more is the high percentage of students who seem not to have the research skills required to reach their goals (many of whom have the nobility to drop out) and the considerable number that are still lacking research skills even while they write up their final dissertations. I suspect we have not been doing a very good job.

To come to terms with this situation, I have been going over all the assessments we make of what we call the students" "minor dissertation", a 30,000 -word research design and pilot study that they have to present within two years of beginning the program. "We" here refers to several examiners of those projects, the main ones being Andrew Chesterman, my late and much regretted colleague Christopher Scott-Tennent, Franz Pöchhacker, Seán Golden and myself. Some evaluations were noted from video recordings of the defense sessions. I have simply noted down the main negative comments and I have tried to arrange them into lists of shortcomings, with little concern for quantitative analysis. That arrangement, with a few suggested causes, is what is reported on in this paper. My wider hope is eventually to convert that negative list into a positive set of skills to be developed, with ideas on how to do the developing. But we are not yet there.

The overall exercise is not as banal as it sounds - if I can isolate skills that are somehow specific to research on translation (here including interpreting and localization), I might have an idea of what Translation Studies is. And that is what is really at stake.

\section{SHORTCOMINGS THAT DO NOT CONCERN TRANSLATION STUDIES}

Unfortunately for most readers of this text, the exercise has confirmed my growing suspicion that the vast majority of the missing skills have remarkably little to do with Translation Studies. This concerns quite elementary things like:

1. attempting to cover enough material for two dissertations;

2. attempting to cover enough material for three dissertations;

3. attempting to cover enough material for four dissertations;

4. choosing a topic for which not enough data is available;

5. choosing a topic for which not enough subjects are available;

6. choosing a topic for which data will cost too much money and/or effort;

7. depending on research methods in which the student has no training ("the statistician will sort it out");

8. choosing a topic because it suits the data-gathering tool you want to use (this mostly happens with corpus linguistics, and more recently with eye-tracking); 
9. tackling too many variables for too few subjects;

10. sampling in an uncontrolled way;

11. believing that "empirical" means quantitative only;

12. using value terms in hypotheses;

13. using categories that give the result before the research is done;

14. taking self-report data (questionnaires and interviews) at face-value;

15. taking your own experience as primary data and as sufficient methodology;

16. mimicking the ideas of your supervisor;

17. never questioning your position as an observer;

18. citing a lot of theory to state the obvious;

19. collecting a lot of data to state the obvious;

20. assuming there is only one cause for a social effect;

21. looking for one thing (e.g. explicitation) without looking for its opposite (e.g. implicitation);

22. assuming the only pertinent contexts are the borders of a nation or a language;

23. believing that research involves no more than "talking about" a topic;

24. coining terms instead of defining concepts.

And a long etcetera. I could get into serious trouble trying to elaborate any one of these, so let me put the list on hold and make the basic point: all of these shortcomings can concern any kind of research in the humanities; as methodology problems, they are not limited to Translation Studies.

A clear consequence of this would seem to be that we do not really need doctoral programs in Translation Studies. Any basic research-training program should be able to address the above problems, so we could send our junior researchers to any basic training program, ideally one that covers research methods for the social sciences.

Such a move would be in tune with the position of the American Translation and Interpreting Studies Association (ATISA 2008) when it declares that research on translation does not require its own disciplinary location: it can be carried out within Linguistics, Literary Studies, Sociology, whatever, and may indeed be better when done within those disciplinary locations. ${ }^{1}$ That argument might be reinforced by the low quality of research done in some Translation Studies programs in Europe - having a named academic niche will not automatically bring quality. At the same time, the convenience of the argument could also partly be explained by the fact that, to the best of my knowledge, in the United States only one dissertation has been defended in a doctoral program called anything like Translation Studies (although dissertations on translation have been carried out in any number of other programs, in Modern Languages, Comparative Literature, Linguistics, Sociology, or Computer Sciences ${ }^{2}$ ). That 
is, the ATISA members would seem to be bulwarking the disciplinary locations in which they themselves were trained and where the vast majority of them now work. And for that matter, bad doctoral research can and does happen anywhere. But the American critics merit a more substantial response.

So why might we still want to have research training specific to Translation Studies? Are there any kinds of problems that do indeed concern translation more than anything else? If so, what kinds of research skills are required to meet those problems?

Here I move on to slightly more interesting parts of the list.

\section{USING UNSTABLE TERMS}

One of the surprising things to emerge from my exercise was the number of times the evaluators asked for clarification of some fairly basic terms. This concerns even a well-established concept like "norm", which since Toury (1995) has been more important for Translation Studies than for any of our neighboring disciplines. No matter how much we might refer back to Toury, each researcher still has to sort out whether norms are qualitative, as in rules that can be broken, or quantitative, as in patterns that emerge when you count sets of things. Failure to do so often results in strange mixes of methodologies and claims. The unnerving thing, though, is that the fault is not so much with the student researcher as with a discipline that has not taken enough time to form consensus around some quite fundamental notions. The concept of norms is in no way specific to translation, of course - it has a lot to do with translation scholars as a group of people who, for a while, somehow thought that this one idea was all the sociology they needed, and they thus invested a whole lot of different things in it.

Other terms like this include:

25. "explicitation", which is used in many different senses and is not infrequently taken to mean "explanation" and sometimes "specification";

26. "translation strategies", which as a concept has grown to the point where it includes the things translators produce, the ways they produce them, the ways they think about producing them, and the things they generally aim to achieve;

27. "culture-specific items", where no one is taking the time to say how they can test the specificity and/or prove the limits of a culture (these two operations mostly form a tautology: we have the same culture for as long as a set of culture-specific things are shared by us);

28. "intentions", but here we get into hermeneutic problems, which we will meet below. 
Many more examples could be added. In all cases, the shortcoming is very probably more with the discipline (or lack of it) than with the student. And the quick solution is probably to insist that student researchers think seriously about the way they want to use the terms (i.e. which specific concepts they need to mobilize), and then provide their own working definitions. That is, we cannot require anyone to set about learning the meanings of technical words (what is lacking is not knowledge as such); we must make them realize that the terms themselves are in flux, authority is not established, and each researcher must be moderately pro-active in this respect.

Of course, a longer-term solution should be for Translation Studies to start cleaning up its act. This means not just collecting the ways different terms have been used (as in Shuttleworth and Cowie 1997 or Palumbo 2009), but also recommending a few usages along the way (as I have started to do in Pym 2011). There is no need to impose fixed meanings for fixed words, as if we were already at the end of our discipline, in a conceptual paradise free of doubt, debate, and dynamism, but there is a need to reduce fruitless confusion.

Gone are the days when we could claim these were the teething problems of a young discipline. We have grown moderately old, and our words are still not staying put.

A minor correlative of terminological flux is the propensity among young researchers - and the not-so-young - to invent not just new terms, which is often quite justified, but to invent whole new avenues of research, not infrequently justified as "turns", comprising a bare word or direction, devoid of identified problems or clear discovery procedures. The rate of these turns is becoming quite dizzying, and many of them should be considered symptoms of rather more than a terminological mess.

\section{CRINGING AT BIGGER DISCIPLINES}

Most of the "turns" involve a desire to draw on insights or concepts from other academic disciplines. The "cultural turn" ran parallel to the rise of Cultural Studies; the "social/sociological turn" is basically a desire to apply the work of sociologists; a "performative turn" takes us into Performance Studies; and a hypothetical "linguistic re-turn" (Vandeweghe et al. 2007) would bring us back to yet another master discipline. Now, there is nothing wrong with drawing on other disciplines; interdisciplinarity is a very healthy thing. Yet it sets traps for beginners, who occasionally disappear into quicksands. Here is a shortlist of what can happen:

29. Believing that all disciplines say the same thing: For example, Bhabha's "third space" in Postcolonial Studies could sound like Turner and Fauconnier's "blended space" in cognitive linguistics, and 
translation can possibly be seen as pervading both concepts, so it's all one blended mess. But the two or three disciplines are working on quite different kinds of problems, and dealing with different kinds of data. If you are going to throw such things together, you must also remain acutely aware of their differences. Make them speak to each other, by all means, but you cannot say they are all the same thing.

30. Playing in a different league: The opposite to the above is to see one discipline's battles as informing all others. For example, a dissertation that defends cognitive linguistics against Chomsky might work in Linguistics, but it is not saying much in Translation Studies. No matter how much you like your football team, you must be aware that it is not playing in all the leagues at the same time.

31. Believing there is only one representative of a discipline. A variant on the above is to take one football team as if it were the whole league. Thus we see Bourdieu being used as the whole of sociology, or Derrida as the whole of philosophy. Thus uncontested, they are heralded into Translation Studies as bearers of established truth.

In all these cases, the remedy is to ensure that students know a lot more about the disciplines they are working with, and that they are much more critical of the apparent authority with which representatives of those discipline are presumed to speak.

In many such cases, the fundamental problem might be the idea that Translation Studies basically has nothing of its own to offer, so any other discipline might be better (rather like the ATISA position outlined above). This belief, which might be well-founded, could also account for a few further tendencies that could be appended here:

32. Disappearing into aporias: Students approaching translation from the perspective of idealist philosophy, anti-idealist philosophy, poetry and all points in between occasionally slip into the great cosmological desert of translation being impossible, or everything being translation, or translators facing dilemmas that no one can resolve. And so their research constantly repeats the aporias, since there is nowhere else to go.

33. Disappearing into data: The opposite of the above is to collect data for data's sake, somehow in the belief that things should be collected if and when they have not been collected before. For instance, it is possible to compare the successive drafts of a translation, to see how a translator has worked. But will that identify or address any problem? Will it find an interested reader? Something further is required if we are to move beyond tedious descriptivism. ${ }^{3}$ 
34. Extending best practices: In the same way as some academic disciplines are assumed superior and worth imitating, so some countries and cultures are accorded axiomatic prestige. Thus we find, in some research proposals, the belief that "best practices" have been established in the advanced post-industrial economies (for example, in localization workflows, or ethics in healthcare interpreting), and those best practices should be implanted everywhere else. This becomes highly problematic if the researcher never asks what "best" means, why current practices are different, and why different societies might rationally choose to distribute their resources in different ways. Here we start approaching the grain.

35. Extending vocational values: Similar to the above, unquestioned authority might be placed in values that are key to the various professions we study: things like efficiency, productivity, attribution of authorship, or linguistic accuracy thus enter as absolutes, since they operate that way in professional life. Research becomes an extension of the translation profession, taking up positions that annihilate its critical capacity and blind many not only to the values of non-professional or volunteer translation, but also to the many good social alternatives to translation (starting from language learning and code-switching).

In all these cases, if you believe that Translation Studies has nothing to offer, then it certainly will have nothing to offer. We might as well be somewhere else: in sociology, literary studies, cognitive science, numbered index cards, the pinnacles of global capitalism, or sublime expert performance. In all these cases, shortcomings ensue because Translation Studies is assumed to have no problem of its own to solve.

\section{THE BUGBEAR OF QUALITY}

In our small corpus of critical comments, the one term that keeps reappearing is "quality". This is mostly because the term is used in an unqualified way to describe what a translation should be like, and this use often happens in main hypotheses (e.g. "translator training is inadequate" or, slightly better, "presence of variable X correlates with better translations"). The general shortcoming might be described as follows:

\subsection{Believing that "Translation Quality" is Self-Evident}

The remedy is, as with almost everything else, for the student to think more, in this case about what quality actually means in the context concerned, and how it 
can be tested. In most research designs this will lead to methodologies where quality is not measured directly by the researcher but is formulated by the subjects who are being studied. That is, quality becomes what some people think quality is. It may be based on ST-TT similarity, on usability of TT, on the translator following a set of instructions and respecting a glossary, or on simply meeting a set of expectations (see Chesterman 2008). In all these cases, quality becomes rigorously not self-evident - problem solved.

The issue of quality nevertheless merits special consideration here. The peculiar thing is not so much that it is frequently mentioned in our evaluations, but that it does not seem to be such a problem in most of our neighboring disciplines, or at least it is not a problem in the same way. A linguist would quite happily look at distribution in a corpus or a string of subjective judgments in order to describe well-formedness; a literary scholar is rarely called on these days to actually evaluate the worth of a text (that kind of thing is for "critics"); a serious sociologist or ethnographer is not going to produce a hierarchy of "high quality" societies or social groups. In sum, the problem of quality is something that Translation Studies has struggled with in a rather special and prolonged way. The reasons for this might be found in some of the reasons listed above, particularly in what I have described as research trying to extend vocational values: since translators are concerned with producing and defending quality, it is felt that translation scholars should do the same thing; or again, since many scholars are also teachers of translation, the urge to correct and improve is poorly suppressed. Those might be social or psychological reasons behind a special engagement with quality, all of them ensuing from what I have described as a general disciplinary cringe. But I think it is worth digging a little deeper.

\subsection{Hiding the Position of the Researcher}

The epistemological problem here basically concerns the belief that a piece of language has only one fixed meaning - the meaning to which a translation can then be more or less adequate. That belief might be regarded as "essentialism". As such, it has received massive philosophical critique for several generations, from camps as apparently wide apart as deconstruction and analytical philosophy. If a researcher must accept that a piece of language does not have just one fixed meaning, then all the suppositions about self-evident quality fall down like a house of cards.

And yet different pieces of language do have different degrees of semantic stability. It is thus possible to make judgments about those pieces with different degrees of externality (understood here as the opposite of subjective involvement). Most of the methodological machinery we have in the social sciences is designed to support and enhance that externality. Thus we have the fixed con- 
cepts of a shared academic discipline; we use terms that are beyond common parlance (thus giving us a "discipline" in every sense of the word); we have the methodologies of surveys and interviews, the counting of things, the imposition of rigorous categories with clear dividing criteria, and the citing of opinions rather than the expressing of our own. This need for externality should explain why young translation scholars tend to attribute authority to other disciplines like Linguistics and Sociology: those disciplines look authoritative in their apparently absolute externality. This might also explain why some beginner researchers mistakenly assume that our own terms are fixed and stable, and why, for example, the problem of quality is apparently solved by the citing (through the methodological machinery) of what others take quality to be. In a sense, becoming a discipline means assuming externality. And the underlying problem of Translation Studies, as a set of research skills, would seem to be the difficulty of assuming that externality.

The repressed, however, returns. Just as the translation scholar has to interpret source texts and translations, since both in principle have multiple possible meanings, so any scholar has to interpret any piece of data, including the pronouncements of apparently authoritative disciplines. As Bourdieu admitted (1980: 22-23), we need the methodological paraphernalia, the "best weapons" developed by our predecessors, in order to promote the illusion of our own objectivity (cf. Pym 1995). The specificity of translation, I propose, is not the presence or absence of externality, but the heightened degree to which our externality is problematic. Precisely because we are working on translations, precisely because we are thus constantly straddling the borders between systems of relative stability, we are especially prone to methodological problems involving our subjective position. Because of this special location, the underlying shortcoming should be seen as the facile assumption of externality.

Let me illustrate this briefly with two cases from published research, not from doctoral students, who have no need to be exposed in this way.

The first one is a citique I am shamelessly rehashing from elsewhere (Pym 2007). It concerns a passage in which the Princeton Professor Emily Apter analyzes a pseudotranslation by the American poet Kenneth Rexroth, who was imitating Japanese erotic verse written by women. The pseudotranslator Rexroth thus invented a Japanese woman poet named Marichiko. Now, Apter uses the machinery of text analysis and literary criticism to compare the pseudotranslation with a poem by the real Japanese woman poet Yosano Akiko. The researcher finds that "the sexual realism of the Marichiko texts to be more graphic, more prone to Orientalist kitsch. [...] On close scrutiny the Marichiko poems fall apart as credible simulations of Japanese women's writing" (2006: 218-219). That is, the "real" poem is better than the pseudotranslation. That would be acceptable enough as a piece of literary criticism. Unfortunately, Apter goes on to make general points about translation, lapsing into uncontrolled 
theorizing: "The revelation of a translational false coin leaves the reader aware of the dimension of epistemological scam or faked-up alterity inherent in all translation"; and here comes the grand critique: "The translation business is geared to keeping this scam from view, for it wants to convince readers that when it markets an author in translation, the translated text will be a truly serviceable stand-in for the original" (2006: 220). So what could possibly be wrong here?

Apter has based all of her analysis and critique on the assumption that the non-pseudotranslation, the poem by Akiko, was authentic as "Japanese women's writing". That is where she has pinned her essentialism and staked out her externality - she knows something that the "translation industry" apparently does not. Of course, the poem by Akiko was a translation (Apter does not tackle any Japanese), and was of course translated by Rexroth (the same man who penned the apparently inferior pseudotranslation). So the entire critique of translation as being a false scam is based on a translation that is accepted as having authentic value. And Apter apparently never saw the problem. She thought her position as a reader was somehow above the workings of translation itself.

My second example concerns research on mistranslations in a Spanish court. Tayseer Allouni, an Al-Jazeera reporter born in Syria and naturalized Spanish, interviewed Osama bin Laden after the 9/11 attacks. He was later accused in Spain of collaborating with a terrorist organization, and the accusation was partly based on translations of taped telephone conversations. Anne Martin and Mustapha Taibi (2010) have analyzed several examples from those translations, using them to criticize - very correctly - the generally poor status of translators and interpreters in the Spanish justice system. For example, they find that the term "abu shabab", which we are told means "mate" or "friend" in the Aleppo region of Syria, was rendered in Spain as "leader of a group of young people" (since in general Arabic "abu" means "father" and "shabab" means "group of people"). So when Allouni was called "abu shabab" in a taped conversation, this was mistakenly construed as evidence that he was the leader of a terrorist cell. So far, so good - or so bad. The researchers then argue that "what clearly shows the framing of this word shabab in terms of the "Guerra contra el Terrorismo' is the series of questions asked by the judge and fiscal: immediately after questions about the young men, there come the questions 'What is Jihad for you?' and 'What does Al Qaeda mean?'” (2010: 220). That is, the mistranslation informed the judge's questions in the trial, creating a "climate of guilt" that was made to fit the US ideology of a War against Terror. In more general terms, translation functioned here as "situation management" or "selective appropriation", seriously compromising justice.

So what could possibly be wrong with this research? Nothing at all is wrong with the researchers' good intentions. And nothing is particularly wrong with their belief in a highly probable understanding of the Arabic fragments, 
even though that understanding is particularly partisan in context: the proposed meaning of "abu shabab" is indeed stable enough. ${ }^{4}$ Neither of the researchers is from the Middle East, and neither had access to the original tapes of the conversations (the tapes were mysteriously lost by the Spanish justice system) - the researchers' most likely access to the stable meaning of the texts was through the defendant, since Allouni himself, who had worked as a translator, had the bad translations publicly questioned and actually had them thrown out of court. The researchers are thus inevitably elaborating the truth of the accused, and they explicitly acknowledge the help received from Allouni's attorney and wife. A certain partisanship was thus unavoidable (you seek help where help is available). The problem, however, comes when the researchers assume that the judge's questions, which could conceivably be seen as much-needed checks on the veracity of the translations, were in fact quite the opposite: here those questions are willfully interpreted as evidence of the way the translations, despite being discounted, shaped the course of the trial. There was apparently just the one "climate of guilt", which was framed by just the one "War on Terror". That is where the researchers have pinned their methodological essentialism; that is where they have precariously assumed that an internally complex system speaks and acts with just one voice, with just one intention. Indeed, that is where simplistic categorization (innocent accused here; guilty system there), as in so much narrative critique, gives the finding before the research is done. An utterance on one side ("abu shabab") is worth investigating in contextual detail; utterances on the other side (the courtroom questions) merit no such investigation. Since the authors start from that ideological divide, no credit is given to the justice system for having eventually recognized the mistranslations; no evidence is given for the blunt assumption that the only pertinent context was the US-led War on Terror. Indeed, the term "War on Terror" tellingly has no fixed translation into Spanish: the "Guerra contra el Terrorismo" referred to by the researchers might also be seen as the long-standing Spanish fight against "terrorism" from Basque independent movement, as indeed might the laws under which Allouni was prosecuted. A culture whose judicial system and procedures date back to the Inquisition does not have to import all its ignominious ignorance of alterity. Indeed, the simple framing in terms of the US-led War on Terror (unproblematically translating "on Terror" as "contra el Terrorismo") possibly has more to do with the context in which the researchers have published their work, as part of a group of activist researchers working on activist translation. ${ }^{5}$

These researchers can thus scarcely pretend to any comfortable exteriority: they are inevitably involved in the object of study. Note that an expert from the University of Granada (the same university as one of the researchers) was called in to comment on the laughable translations; and the ensuing public criticism was probably the reason why the justice system paid impeccable attention to translators and interpreters at the trials following the 2004 Madrid train bomb- 
ings (as the researchers do indeed recognize). Criticism and research is part of the translation institution; we are in the object of study. Indeed, critical reflection could have taken the researchers further in this sense. If they had considered the demographic reasons why many translators and interpreters working for the justice system are mostly untrained, they might have realized that very few training programs are easily accessible to those paraprofessionals in the language combinations required, and that part of any future improvement must involve the very training institutions in which the researchers work. Instead of recognizing this implication, here we have one-sided condemnation. No attempt is made to decide whether this is a case of translatorial incompetence or inquisitorial manipulation - it is both, apparently, and at the same time, since only the researchers' side knows and appreciates the truth of the foreign utterance and the motivations behind courtroom questions, and all else is global ignorance. Now, journalists are trained to seek both sides of a story (which would indeed have been the best justification for anyone to interview Osama bin Laden), and they know that they are in the story. These translation researchers seem not to have been attuned to those problematics. In this case, the researchers themselves are transparently engaging in situation management and selective appropriation - their essentialism is no more neutral than are the errors of the translators and judicial officials whose work they rightly lament.

(I take this example from Spain so as not to presume to know about South Africa. But it should be very clear that if you are doing research on translation to or from Afrikaans, or any other official language of South Africa, you are immediately part of cultural politics: translators and researchers are both in the same department, with the same training, and are often the same person - the illusory comfort of externality is simply not available.)

How should researchers avoid these methodological pitfalls? The skills to be developed, I suggest, involve an acute and subtle capacity for self-reflection and self-critique, which should be part-and-parcel of openness to research as a collective creation of knowledge. Those skills should extend well beyond the growing art of writing research as propaganda.

\section{CONCLUSION: WHAT WE NEED TRAINING IN}

The long list of shortcomings, many of them quite fundamental, probably suggests we need training in everything. Of course, not all researchers need all the skills, and many of the problems can be solved by sending doctoral students to general training programs in the social sciences (if and when such programs are available).

At the same time, I have argued that the problems of translation research are particularly marked by issues of quality, by a heightened level of cultural 
relativism, and by the need to reflect on any apparent externality. In short, translation research, by its very nature, requires a strong hermeneutic component (if we can remember what that means). that

The ATISA critique of doctoral programs in Translation Studies claimed

[...] many of the more "traditional" programs in TIS [Translation and Interpreting Studies], including many of those existing in Europe, have unfortunately isolated themselves from relevant research and theory in other disciplines. For this reason, many students graduating from these programs are unprepared to conduct the rigorous, principled research essential to informing and growing the field of translation and interpreting studies. [...] Graduating TS PhDs who are unable to produce work that meets the general standards of other fields can do more harm to TS than not producing them. (2008)

Those are fighting words; they merit a vigorous reply. When ATISA refers to "rigorous, principled research" and "the general standards of other fields", they somehow assume that research is the one thing, across the board, in any discipline. To a degree, they are quite right: the vast majority of our shortcomings do indeed concern the transgressing of general scientific principles and a failure to meet widely accepted standards: everything in the first three sections above would fall into that wide basket. At the same time, however, if the particular position of translation research with respect to quality, relativity and externality is not recognized - that is, if all research is simply a question of meeting "general standards" inherited from positivist behaviorism - then the American critique risks radically de-intellectualizing Translation Studies, reducing a dynamic and socially engaged discipline to an affair of standardized dataprocessing.

\section{ACKNOWLEDGEMENTS}

Many thanks to Andrew Chesterman, Carlos Teixeira and Lauretta Clough for comments on earlier drafts of this text.

\section{Notes}

\footnotetext{
1 "We agree that the establishment of doctoral programs in translation and interpreting studies is a highly desirable way to prepare future researchers in TIS. However, evidence shows that this can also be successfully accomplished through doctoral programs in related fields, as demonstrated by excellent work in TIS done by researchers trained through other types of programs." (ATISA 2008)
} 
${ }^{2}$ For example, Claudia Angelelli's dissertation Deconstructing the Invisible Interpreter (2001) was carried out in the School of Education at Stanford; Lauretta Clough's Translating Pierre Bourdieu (1998) was defended in the French program at the University of Maryland.

${ }^{3}$ An associated problem here is the tendency to count linguistic items as if they were all of the same value, imposing quantitative methods on intrinsically qualitative data. For example, when quantitative corpus analysis shows that one translation is more literal than another, and yet critical reviews all say the opposite, who is right?

${ }^{4}$ My own informant from the Aleppo region states that "abu shabab" is used in the way that a respect-filled "mate" might be used in Cockney or Australian English.

${ }^{5}$ Martin and Taibi finish their article by citing Maria Tymoczko, "translation is a partisan activity", and they might happily add that translation research is also a partisan activity. However, they are clearly uncomfortable with outright partisanship by translators in the justice system: they do reproduce the ideal of a "faithful translation" (as not being the same thing as a "literal translation") and they state that "neutrality is complex", without ever actually saying that it is impossible. If you radically believe that all attempts at neutrality merely reproduce "the dominant discourse of the dominant social powers" (2010: 224), then you should probably not participate in any justice system and you should start planting bombs. More thought is required.

\section{References}

ATISA. 2008. Statement on PhD training in Translation and Interpreting Studies. November 14, 2008: http:/groups.yahoo.com/group/itit/message/2035. Accessed March 2012.

Bourdieu, P. 1980. Une science qui dérange. Interview with Pierre Thuillier, La Recherche 112 (June 1980). Reprinted in Questions de sociologie. Paris: Minuit. 19-36.

Chesterman, A. 2008. Functional quality. Video lecture at http://www.facebook.com/video/ video.php?v=1082863408296. Accessed March 2012.

Martin, A. Taibi. M. 2010. Traducción e interpretación policial en contextos politizados: El caso de Taysir Alouny. In: Boéri, J., Maier, C (eds) Compromiso social y traducción/ interpretación-Translation/Interpreting and Social Activism. Granada: ECOS. 214-225.

Palumbo, G. 2009. Key terms in Translation Studies. London and New York: Continuum.

Pym, A. 1995. European Translation Studies, une science qui dérange, and Why Equivalence Needn't Be a Dirty Word., TTR Vol. 8. No. 1. 153-176.

Pym, A. 2007. Review of Emily Apter The Translation Zone. A New Comparative Literature. Target Vol. 19. No. 1. 177-182.

Pym, A. 2011. Translation research terms - a tentative glossary for moments of perplexity and dispute. Pym, A. (ed.) Translation Research Projects 3. Tarragona: Intercultural Studies Group. 75-99.

Shuttleworth, M., Cowie, M. 1997. Dictionary of Translation Studies. Manchester: St Jerome.

Toury, G. 1995. Descriptive Translation Studies and beyond. Amsterdam and Philadelphia: John Benjamins.

Vandeweghe, W., Vandepitte, S., Van de Velde, M. 2007. Introduction: A Linguistic 'Re-turn' in Translation Studies? Belgian Journal of Linguistics Vol. 21. No. 1 1-10. 